\title{
Coriocarcinoma: um estudo de caso
}

\author{
Choriocarcinoma: a case study
}

Coriocarcinoma: un estudio de caso

\section{Pollyana Alves Silva', Sueli Riul da Silva'}

'Universidade Federal do Triângulo Mineiro. Curso de Graduação em Enfermagem. Uberaba, MG

Submissão: 10/08/2008

Aprovação: 20/01/2010

\section{RESUMO}

O presente estudo objetivou descrever o caso de uma cliente portadora de coriocarcinoma gestacional e a assistência de enfermagem necessária a esta condição. A partir de informações constantes do prontuário médico e de anamnese e exame físico realizados em visita domiciliária, formularam-se diagnósticos e intervenções de enfermagem embasados na literatura. Foram identificados diagnósticos referentes aos períodos perioperatório e de tratamento Quimioterápico. Além dos diagnósticos referidos, foi possível identificar outros relativos ao período pós-tratamento da cliente. O processo de enfermagem mostrou-se efetivo para a assistência Qualificada à cliente com coriocarcinoma.

Descritores: Coriocarcinoma; Estudos de caso; Enfermagem.

\section{ABSTRACT}

The present study aimed at describing the case of a client bearer for gestational choriocarcinoma and the nursing assistance needed for this condition. From information contained in the medical history and of anamnesis and physical examination made in a home visit, made up diagnoses and inteventions of nursing based in literature. Diagnoses have been identified related to the periods perioperative and chemotherapy treatment. In addition to these diagnoses, it was possible to identify others on the post-treatment period of client. The process of nursing proved to be effective for the eualified assistance for the client with choriocarcinoma.

Key words: Choriocarcinoma; Case studies; Nursing.

\section{RESUMEN}

El presente estudio objetivó describir el caso de una cliente portadora de coriocarcinoma gestacional y la asistencia de enfermería necesaria a esta condición. A partir de informaciones constantes del prontuario médico y de anamnese y examen físico realizados en visita domiciliaria, se formularon diagnósticos e intervenciones de enfermería embasados en la literatura. Fueron identificados diagnósticos referentes a los períodos perieuirúrgico y de tratamiento Quimioterápico. Además de los diagnósticos referidos, fue posible identificar otros relativos al período pos-tratamiento de la cliente. El proceso de enfermeria se mostro efectivo para la asistencia calificada a la cliente con coriocarcinoma.

Descriptores: Coriocarcinoma; Estudios de caso; Enfermería. 


\section{INTRODUÇÃO}

As doenças trofoblásticas gestacionais compreendem lesões caracterizadas pelo desenvolvimento anormal do trofoblasto e incluem mola hidatiforme (parcial e completa), mola invasora e coriocarcinoma, todas produtoras de gonadotrofina coriônica humana - hCG ${ }^{(1,2)}$.

A mola hidatiforme é a forma benigna e não-invasiva, caracterizada pela degeneração hidrópica das vilosidades coriônicas. O tratamento inclui esvaziamento cirúrgico e monitoração dos níveis de â-hCG pós-esvaziamento, além de Quimioterapia Quando os níveis de â-hCG se elevam e atingem um platô ou surgem metástases. As pacientes não podem engravidar no período de um $\mathrm{ano}^{(3)}$.

lá a mola invasora, biologicamente benigna, invade a parede uterina e pode romper o útero, causando hemorragias. As vilosidades hidrópicas da mola invasora podem atingir sítios distantes, onde, apesar de não crescerem, podem causar complicações advindas da obstrução vascular dos órgãos ${ }^{(1,2)}$. O tratamento compreende a histerectomia e Quimioterapia ${ }^{(3)}$.

O coriocarcinoma é a condição maligna entre as doenças trofoblásticas gestacionais e pode seguir Qualeuer forma de gravidez previamente normal ou anormal, sendo Que 50\% surge após uma mola hidatiforme, $25 \%$ deriva de abortos espontâneos; $22,5 \%$ de gestações normais e $2,5 \%$ de gestações ectópicas. Estima-se Que uma em 40 molas hidatiformes desenvolva-se em coriocarcinoma, contra uma em 150.000 gestações normais anteriores. O coriocarcinoma apresenta baixa incidência, ocorrendo em uma entre 20.000 a 30.000 gestações nos Estados Unidos ${ }^{(1,2)}$.

O coriocarcinoma possui manifestações variadas e seu reconhecimento se torna ainda mais difícil Quando não é precedido por mola hidatiforme. Classicamente, o útero apresenta-se aumentado, o sangramento vaginal persiste e os níveis de hCG não negativam $^{(2)}$. Os sinais sugestivos de metástase são hemorragia intraabdominal, tosse, hemoptise, dor pleurítica, dispnéia e insuficiência respiratória nos casos de comprometimento pulmonar; manifestações gastrointestinais, como hematêmese e melena; além de lesões vaginais e sinais de envolvimento cerebral ${ }^{(2,3)}$

O diagnóstico é estabelecido a partir de exames laboratoriais Que dosam os níveis de hCG no plasma, também usado para controle da doença após o tratamento, além da ultrassonografia e exame anátomo-patológico. O crescimento primário no útero pode não estar presente, existir sob formas incomuns ou ter involuído espontaneamente após metastatizar-se, por isso, muitas vezes, o diagnóstico é feito tardiamente ${ }^{(1,2,4)}$.

O exame patológico mostra um tumor mole, carnudo e amareloesbraneuiçado, podendo apresentar áreas de necrose. A microscopia revela elementos citotrofoblásticos e sinciciotrofoblásticos, sem vilosidades reconhecíveis ${ }^{(1)}$.

O tratamento é baseado no tipo e estadiamento do tumor. Compreende esvaziamento do conteúdo uterino, histerectomia e Quimioterapia ${ }^{(1,2)}$. Há vários esQuemas de Quimioterapia, entre eles o metotrexate $30 \mathrm{mg} / \mathrm{m}^{2}$ intramuscular semanalmente e o metotrexate $1 \mathrm{mg} / \mathrm{kg}$ em dias alternados, durante Quatro dias, seguido de leucovorina (24 horas após o metotrexate) na dose de $0,1 \mathrm{mg} / \mathrm{kg}$ endovenosa. Os esQuemas continuam até a negativação dos níveis de â-hCG por três semanas consecutivas, a partir disso, as clientes devem ser monitoradas mensalmente durante um ano. Nos casos das clientes com tumores de alto risco (níveis de â-hCG muito elevados, apresentação da doença Quatro meses ou mais após gravidez prévia, metástase para cérebro ou fígado ou falta de resposta a tratamento com metotrexate isolado) o tratamento inclui Quimioterapia combinada, entre elas o esQuema MAC (metotrexate, actinomicina D e ciclofosfamida) administrado a cada três semanas, até normalização dos níveis de â-hCG e o esquema EMA-CO (etoposida, metotrexate e actinomicina D, alternada com ciclofosfamida e vincristina), menos tóxico que o $\mathrm{MAC}^{(3)}$.

O índice de cura ou remissão da doença com Quimioterapia é de até 100\%, exceto naquelas clientes com mau prognóstico. Estudos demonstram que clientes curadas não apresentam, a longo prazo, maior risco de complicações maternas ou fetais nas gestações subsequentes ${ }^{(1)}$

As responsabilidades do enfermeiro no cuidado à cliente com coriocarcinoma incluem conhecer a fisiopatologia do processo, utilizar os achados de pesQuisa e práticas atuais, garantir assistência de enfermagem individualizada e humanizada, avaliar as necessidades do cuidado de enfermagem, identificar os problemas de enfermagem da cliente e da família, planejar as prescrições de enfermagem, colaborar com a equipe multidisciplinar, implementar ações educativas, assistenciais e administrativas em relação à cliente, família e funcionários; avaliar os resultados obtidos com o cuidado, auxiliar nos desejos de aprendizagem da cliente e família, avaliar a capacidade da cliente em lidar com as alterações da imagem corporal, avaliar o impacto psicológico da doença sobre a cliente e família, cuidados com a Quimioterapia (efeitos colaterais, complicações, medidas de segurança), além de assistência ao perioperatório nos casos de cirurgia ${ }^{(5-7)}$.

Dado que a literatura específica da área de assistência de enfermagem em onco-ginecologia é escassa no Que se refere à sistematização da assistência de enfermagem (SAE), direcionada à mulher portadora de coriocarcinoma gestacional, o presente estudo justifica-se por possibilitar o levantamento de informações pertinentes e descrição de proposta de SAE, uma vez Que se apresenta a oportunidade de acompanhar um caso clássico de cliente portadora da doença, apresentando sua completa história natural.

\section{OBIETIVOS}

Elaborar um estudo exemplar sobre coriocarcinoma e descrever as práticas assistenciais de enfermagem necessárias a clientes portadoras dessa neoplasia.

\section{METODOLOGIA}

Trata-se do estudo de caso de uma cliente com o diagnóstico de coriocarcinoma gestacional, atendida na Enfermaria de Ginecologia e Obstetrícia do Hospital Escola da Universidade Federal do Triângulo Mineiro - EGO/HE/UFTM, em Uberaba MG. Para confecção do estudo de caso utilizou-se as orientações de Galdeano et $\mathrm{al}^{(8)}$.

Os dados foram obtidos a partir de formulário para entrevista e roteiro para exame físico - elaborados com base na literatura específica da área ${ }^{(9)} \mathrm{e}$ aplicados durante duas visitas domiciliares à cliente e, a partir de informações contidas no prontuário da mesma. 
Posteriormente, foi realizada a descrição dos dados, identificação dos problemas, com base na proposta de Wanda de Aguiar Horta ${ }^{(10)}$, formulação dos diagnósticos de enfermagem, com base no referencial teórico da North American Nursing Diagnosis Association - NANDA ${ }^{(1)}$ e proposta de intervenções de enfermagem.

Para desenvolvimento do presente estudo foi solicitado e concedido parecer e aprovação do Comitê de Ética em Pesquisa com Seres Humanos - CEP, da UFTM.

\section{RESULTADOS}

\section{Apresentação do caso}

Cliente de 38 anos, de cor branca, procedente de UberabaMG, casada, atendente de loja, é G6 P2(CIN I), A4, 0 I natimorto e 01 nascido vivo.

Em 14/02/2005 grávida de três meses, sofreu aborto e foi submetida à curetagem a vácuo em serviço facultativo, cujo exame anátomo-patológico mostrou mola hidatiforme parcial.

Em 3 I/03/2005 procurou o pronto socorro do HE/UFTM referindo dor e sangramento transvaginal há um mês, sendo hospitalizada na EGO do mesmo serviço para avaliação.

No dia 04/04/2005, após laudo de ultrassonografia (US) pélvica compatível com mola hidatiforme e resultado Quantitativo de âhCG mostrando nível elevado $(93.937,0 \mathrm{mUl} / \mathrm{ml})$, iniciou-se esquema semanal de nove ciclos de Quimioterapia com $90 \mathrm{mg}$ metotrexate.

Em 05/04/2005 procurou o pronto socorro do HE/UFTM Queixando fraqueza intensa há 06 horas e perda de sangue transvaginal em grande Quantidade e com coágulos, sendo então encaminhada para hospitalização na EGO.

No dia 1 1/04/2005 foi administrado $2^{\circ}$ ciclo de Quimioterapia e em 12/04/2005 recebeu alta hospitalar.

O resultado do -hCG mostrou-se negativo em 27/05/2005 e recebeu o último ciclo do esquema de Quimioterapia com metotrexate em 03/06/2005.

Em consulta de acompanhamento na onco-ginecologia do serviço, no dia 10/06/2005, após análise de â-hCG do dia 03/06/2005 (180mUl/ml), são prescritos mais Quatro ciclos de Quimioterapia, completando-se um esquema de 13 ciclos.

Após o término do tratamento com Quimioterapia, o resultado do â-hCG (08/07/2005) mostrou-se negativo. A cliente foi então encaminhada para acompanhamento mensal na onco-ginecologia.

A partir de 17/07/2006 os níveis de â-hCG começam a elevarse progressivamente e o laudo de US pélvica, do dia 20/10/2006, sugeriu recidiva de mola. Em 26/10/2006 a cliente foi hospitalizada.

Em 31/10/2006, a cliente foi submetida à histerectomia abdominal total e salpingectomia bilateral, sem intercorrências, sendo o material ressecado encaminhado para exame anátomopatológico. No pós-operatório a cliente apresentou-se ansiosa e polieueixosa, referindo dor intensa e sensação de náusea.

No dia 02/1 1/2006 recebeu alta hospitalar e foi orientada a dar seguimento ao acompanhamento semanal na onco-ginecologia.

Após dois resultados sucessivos de â-hCG negativos, em 09/ 1 1/2006 e 22/1 1/2006, os níveis tornaram a elevar-se.

Em 30/11/2006, o laudo anátomo-patológico do material colhido na cirurgia definiu diagnóstico de coriocarcinoma, medindo
I $x \mid \times 0,8 \mathrm{~cm}$ e infiltrando terço superficial do miométrio. Foram prescritos Quatro ciclos de Quimioterapia, esquema EMA-CO (etoposide 170mg, metotrexate $170 \mathrm{mg}$ seguido de $340 \mathrm{mg}$ em infusão contínua, actinomiocina D $0,85 \mathrm{mg}$, vincristina $1,7 \mathrm{mg}$ e ciclofosfamida 1020mg), iniciado em 01/02/2007 e com término em 04/05/2007.

Os exames rotineiros realizados no decorrer do tratamento Quimioterápico evidenciaram anormalidade somente na série vermelha, como demonstra o exame do dia 08/04/2005 (hemácias: 2.06 milhões $/ \mathrm{mm}^{3}$; hemoglobina: $5.3 \mathrm{~g} \%$ e hematócrito: 16.9\%). A cliente também foi submetida a radiografias de tórax rotineiras para pesquisa de metástases pulmonares e todos os laudos mostraram normalidade.

No momento de administração da Quimioterapia, a cliente apresentou náuseas, vômitos, perda de apetite e cefaléia.

Após o tratamento, os níveis de â-hCG permaneceram negativos, sendo o último resultado, aquele de 13/1 I/2007 (<1). A cliente manteve controle mensal até dezembro de 2007, bimestral de dezembro de 2007 a julho de 2008; após esse período dois controles semestrais e a partir de então, controles anuais por período indeterminado.

Ademais da assistência de enfermagem prestada em todos os momentos de atendimento intra-hospitalar, foram realizadas duas visitas domiciliares à cliente para entrevista e exame físico.

A comunicação foi facilmente estabelecida na entrevista. A residência da cliente é adęuada en৫uanto acomodação apropriada ao bem estar e saúde. A cliente é consciente do seu estado de saúde-doença e procura informações com profissionais e na internet, não apresentando dúvidas sobre a doença e seu tratamento.

Relatou menarca aos 15 anos, pubarca aos 13 anos e data da última menstruação em 15/10/2006 aos 37 anos. Negou mastite, mastalgia, secreção ou nódulo mamário. Teve sua primeira relação sexual aos 18 anos e referiu ter vida sexual satisfatória. Relatou secreção vaginal patológica prévia, de cor amarelo-esbranquiçada, de odor fétido e com prurido. Referiu ter apresentado Pthirus púbis (popularmente conhecido como "piolho chato") em pêlos pubianos há cerca de 17 anos. A cliente relatou ter amamentado sua filha durante seis meses. Possui bom relacionamento familiar e social. Ingere Quatro refeições por dia, com média Quantidade de verduras, frutas, gorduras, proteínas e carboidratos. Não faz uso de medicamentos. Não realiza atividades físicas regulares, devido à falta de tempo. Não fuma, não usa drogas ilícitas e bebe socialmente nos fins de semana. Realizou Quatro curetagens uterinas após abortos, cirurgia de hemorróida, histerectomia total abdominal e salpingectomia bilateral. Relatou antecedentes mórbidos pessoais de gastrite e pneumonia, e antecedentes familiares de neoplasia, hipertensão arterial e Doença de Chagas.

Durante o tratamento Quimioterápico referiu ter apresentado frąueza, cansaço, náuseas, vômitos, anorexia, constipação, edema generalizado e alopecia.

A cliente manifestou contentamento de ter participado da entrevista, pois considerou o momento oportuno para falar sobre o problema pelo Qual passou.

Ao exame físico, a cliente apresentou-se em bom estado geral. Exibiu tipo físico morfológico normolíneo, boa postura, fácie normal, $80 \mathrm{~kg}$ de peso e $1,65 \mathrm{~m}$ de estatura, circunferência abdominal de $104 \mathrm{~cm}$. Presença de cabelos curtos, castanhos, ondulados, em 
média Quantidade, com distribuição homogênea e limpos; pêlos castanho-escuros, em pequena Quantidade em membros superiores e inferiores; unhas curtas, limpas e sem alterações. Apresentou a pele sem alterações Quanto à coloração, umidade, turgor, elasticidade, mobilidade, sensibilidade, textura, espessura, temperatura e integridade, além da ausência de lesões elementares. A cliente possuía mucosas de coloração e umidade normal, sem lesões. Exibiu tecido celular subcutâneo e panículo adiposo com distribuição e Quantidade normal; musculatura normodesenvolvida Quanto à troficidade e tonicidade. Não apresentou gânglios palpáveis, circulação colateral, edema, icterícia ou febre (temperatura axilar de $36,8^{\circ} \mathrm{C}$ ). Com relação ao sistema respiratório, apresentou tórax normolíneo, ausência de abaulamentos ou depressões, respiração do tipo costal superior e superficial, ritmo respiratório normal, freeüência respiratória de 16 rpm, ausência de tiragem; à palpação, expansibilidade e mobilidade preservadas, e frêmito toracovocal sem alteração; à ausculta, presença de murmúrios vesiculares e ausência de ruídos adventícios; som claro pulmonar à percussão.

$\mathrm{Na}$ avaliação do sistema cardiovascular apresentou ictus cordis localizado no cruzamento da linha hemiclavicular com o Quinto espaço intercostal, com extensão correspondendo a duas polpas digitais e com mobilidade preservada, ausência de frêmito cardiovascular; à ausculta, presença de bulhas normofonéticas a dois tempos, batimentos regulares a $72 \mathrm{bpm}$, ausência de sopros ou ruídos; pressão arterial sistólica de $140 \mathrm{mmHg}$ e diastólica de $90 \mathrm{mmHg}$. Apresentou abdome de forma e volume normal, e cicatriz umbilical levemente retraída; ausência de abaulamentos, retrações, movimentos respiratórios, pulsações ou peristaltismo visível; à ausculta, ruídos hidroaéreos presentes (10/min); à percussão macicez hepática e esplênica, e timpanismo do estômago e cólon; abdome indolor à palpação, normotenso, com parede contínua, ausência de massas pélvicas, gânglios inguinais não-palpáveis; à palpação profunda, fígado e baço sem alterações.

A cliente mostrou-se colaborativa e comunicativa durante a realização do exame físico.

\section{Planejamento da assistência de enfermagem}

O processo de enfermagem, segundo Wanda Horta, "é a dinâmica das ações sistematizadas e inter-relacionadas, visando a assistência ao ser humano" ${ }^{(10)}$. Compreende seis etapas: histórico de enfermagem, Que abrange o levantamento de dados; diagnóstico de enfermagem, elaborado a partir da análise dos dados; plano assistencial, Que envolve a definição global da assistência de enfermagem; prescrição de enfermagem, responsável por determinar as ações de enfermagem para implementação do plano assistencial; evolução de enfermagem, através de relatório diário sobre o paciente; e, por último, prognóstico de enfermagem, Que avalia o atendimento das necessidades humanas básicas do indivíduo a partir da implementação do plano assistencial ${ }^{(10)}$.

A conQuista da sistematização em enfermagem permite o planejamento de uma assistência integral, individualizada, contínua, objetiva e segura ao cliente, além de fazer com que o enfermeiro necessite atualizar seus conhecimentos teóricos, práticos e culturais $^{(6)}$

O desenvolvimento de uma enfermagem embasada em conhecimento científico requer a escolha de um método de trabalho com fundamentação teórica. Nesse trabalho, foram utilizados o referencial teórico de Wanda de Aguiar Horta ${ }^{(10)}$ e da North American Nursing Diagnosis Association- NANDA ${ }^{(11)}$.

As necessidades humanas básicas, utilizadas por Wanda de Aguiar Horta, segundo a teoria de Maslow, "são tensões, conscientes ou inconscientes, resultantes dos desequilíbrios homeodinâmicos dos fenômenos vitais" ${ }^{\prime(10)}$. Foram hierarquizadas em necessidades fisiológicas, de segurança, de amor, de estima e de auto-realização. As necessidades humanas básicas são universais, inter-relacionadas; influenciadas pela individualidade, sexo, idade, cultura, escolaridade, fatores sócio-econômicos, ciclo saúde-enfermidade e ambiente físico, além de nunca serem satisfeitas completa ou permanentemente ${ }^{(10)}$. A enfermagem é responsável por assistir o ser humano no atendimento das suas necessidades humanas básicas.

O diagnóstico de enfermagem foi definido pela North American Nursing Diagnosis Association (NANDA), como sendo "um julgamento clínico das respostas do indivíduo, da família ou da comunidade aos processos vitais ou aos problemas de saúde atuais ou potenciais, os Quais fornecem a base para a seleção de intervenções de enfermagem para atingir resultados, pelos Quais o enfermeiro é responsável”(6). Para o desenvolvimento desses diagnósticos, o enfermeiro deve possuir conhecimento científico, prático, auto-conhecimento, análise crítica e capacidade de tomada de decisões.

Os diagnósticos de enfermagem do presente estudo foram divididos em três períodos: perioperatório, Quimioterapia e póstratamento.

Os diagnósticos e plano assistencial de enfermagem foram dispostos em Quadros para facilitar o entendimento e ordenados segundo a hierarQuização das necessidades humanas básicas de Maslow, conforme Wanda de Aguiar Horta ${ }^{(10)}$.

O Quadro I (em anexo) mostra os diagnósticos de enfermagem, suas características definidoras, fatores relacionados ou fatores de risco e a necessidade humana básica afetada no período perioperatório de realização da histerectomia abdominal total e salpingectomia bilateral. Foram identificados sete diagnósticos: risco de volume deficiente de líquido, náusea, risco de infecção, integridade tissular prejudicada, risco de lesão perioperatória de posicionamento, ansiedade e dor aguda.

No Quadro 2 (em anexo), foi descrito o plano assistencial de enfermagem Que inclui meta, objetivos e intervenções de enfermagem para os diagnósticos identificados nessa fase.

Podemos observar a inter-relação entre as necessidades humanas básicas, como o observado em prescrições comuns para ansiedade e dor aguda. O Que vai de encontro ao conceito holístico do homem, Que deve ser visto como um todo. Algumas necessidades possuem relação mais estreita entre si Que outras, porém todas sofrem modificações, em menor ou maior grau, Quando alguma se manifesta.

lá nos Quadros 3 e 4 (em anexo) são descritos os diagnósticos e plano assistencial de enfermagem durante o tratamento Quimioterápico da cliente. Foram levantados oito diagnósticos: constipação, volume excessivo de líQuidos, náusea, nutrição desecuilibrada - menos do eue as necessidades corporais, fadiga, intolerância à atividade, distúrbio na imagem corporal e risco de infecção. Os diagnósticos comuns entre as duas fases foram náusea e risco de infecção. 
Nos diagnóstico de fadiga e intolerância à atividade, algumas prescrições são comuns, como em relação à dieta rica em ferro para tratar a anemia - uma das manifestações da toxidade hematológica dos Quimioterápicos, Que se manifesta através do cansaço e fraqueza ${ }^{(6)}$, características definidoras da fadiga e intolerância à atividade, respectivamente.

Durante a Quimioterapia existem procedimentos Que devem ser seguidos pela equipe de enfermagem no preparo e administração dos Quimioterápicos, entre eles: lavar as mãos antes e após manipulação da medicação, restringir acesso à área de preparação dos Quimioterápicos, usar luvas durante o manuseio da medicação, usar técnica asséptica na preparação da medicação, usar material absorvente sobre a área de preparação, fazer assepsia da ampola antes de Quebrá-la, identificar todos os Quimioterápicos, limpar respingos imediatamente, transportar os medicamentos em bandejas impermeáveis, usar equipamentos de proteção - luvas, avental e máscara, durante a administração do Quimioterápico, usar material absorvente sob os tubos durante a administração a fim de captar QualQuer vazamento, manuseio e manutenção de cateteres implantados, punção correta, curativo dos cateteres, manuseio de bombas de infusão, monitoramento de sinais vitais, monitoramento de exames - hemograma e bioquímica, observar estado geral da cliente, conhecer propriedades da droga utilizada - diluição, estabilidade, efeitos colaterais, conservação, interação medicamentosa, via de administração, realizar orientações Quanto à ação dos Quimioterápicos e seus efeitos colaterais, descartar dispositivos e medicamentos não-usados de acordo com normas de resíduos perigosos, prevenir e tratar extravasamento, observar reações anafiláticas e instituir tratamento imediato ${ }^{(6,12)}$.

Os diagnósticos de enfermagem referentes ao período póstratamento, representados nos Quadros 5 e 6 (em anexo), foram nutrição desequilibrada - mais do Que as necessidades corporais e estilo de vida sedentário, evidenciados principalmente pelo sobrepeso da cliente.

O aumento da obesidade e sobrepeso na população brasileira aumentou consideravelmente entre a década de 70 e 90 . Fato explicado pelo estilo de vida adotado por parcela significativa da população, como alimentar-se fora de casa ou com refeições rápidas (fast food), consumir em maior Quantidade e produtos mais calóricos, como os industrializados e processados; uso de equipamentos domésticos que diminuem a necessidade de esforço físico, deslocamentos com automóveis e falta de tempo para atividades físicas diárias ${ }^{(14)}$.

O plano assistencial de enfermagem, descrito no Quadro 6, envolve mudanças simples nos hábitos alimentares e no nível de atividade física da cliente.

\section{CONSIDERAÇÕES FINAIS}

A cliente referiu ter recebido assistência adequada e apoio familiar durante tratamento da doença. Atualmente, encontra-se em bom estado geral, relatou estar totalmente recuperada da doença e satisfeita com sua condição de saúde.

O planejamento em enfermagem, através da sistematização da assistência, permite uma melhor orientação do trabalho da equipe de enfermagem e avaliação dos resultados alcançados, especificamente no coriocarcinoma devido à grande demanda por assistência de enfermagem.

Além disso, o planejamento em enfermagem possibilita uma maior valorização do profissional enfermeiro, pois este passa a participar ativamente das prescrições de cuidado ao cliente e a ampliar continuamente seus conhecimentos técnico-científicos.

\section{REFERÊNCIAS}

I. Cotran RS, Kumar V, Collins T. Robbins: patologia estrutural e funcional. $7^{\mathrm{a}}$ ed. Rio de Janeiro: Guanabara Koogan; 2007.

2. Rezende I, Montenegro CAB. Obstetrícia fundamental. $10^{\mathrm{a}} \mathrm{ed}$. Rio de Janeiro: Guanabara Koogan; 2006.

3. Isselbacher KJ. Harrison: medicina interna. $18^{\mathrm{a}}$ ed. Rio de Janeiro: McGraw-Hill; 2005.

4. Pinotti JA, Fonseca AM, Bagnoli VR. Tratado de ginecologia: condutas e rotinas da disciplina de ginecologia da Faculdade de Medicina da Universidade de São Paulo. Rio de Janeiro: Revinter; 2005.

5. Smeltzer SC, Bare BG. Brunner \& Suddarth - Tratado de Enfermagem Médico-Cirúrgica. $10^{a}$ ed. Rio de Janeiro: Guanabara Koogan; 2004.

6. Ayoub AC. Planejando o cuidar na enfermagem oncológica. São Paulo: Lemar; 2000.

7. Silva SR, Aguillar OM. Assistência de enfermagem em Quimioterapia antineoplásica. Rio de laneiro: EPUB; 2001.

8. Galdeano LE, Rossi LA, Zago MMF. Roteiro institucional para a elaboração de um estudo de caso clínico. Rev Latino-am Enfermagem 2003; 1 I (3): 37 I-5.

9. Porto CC. Semiologia médica. $5^{\mathrm{a}}$ ed. Rio de Janeiro: Guanabara Koogan; 2005.

10. Horta WA. Processo de enfermagem. São Paulo: EPU; 2001 .

11. Correa C (trad.). Diagnósticos de enfermagem da NANDA: definições e classificações 2005-2006. Porto Alegre (RS): ARTMED; 2006.

12. Otto SE. Oncologia. Rio de Janeiro: Reichmann \& Affonso Editores; 2002.

13. Jonhson M. Diagnósticos, resultados e intervenções de enfermagem: ligações entre NANDA, NOC E NIC. Porto Alegre: ARTMED; 2005.

14. Mendonça CP, Anjos LA. Aspectos das práticas alimentares e da atividade física como determinantes do crescimento do sobrepeso/ obesidade no Brasil. Cad Saúde Pública 2004; 20(3): 698-709. 
ANEXOS I E 2

\begin{tabular}{|c|c|c|c|}
\hline Diagnóstico & Características definidoras & Fatores relacionados & Necessidade humana básica afetada \\
\hline $\begin{array}{l}\text { Risco de volume deficiente } \\
\text { de líeuido }\end{array}$ & & $\begin{array}{l}\text { cirurgia ( } 15 \text { a } 20 \% \text { da volemia são perdidos durante o } \\
\text { procedimento) } \\
\text { cirurgia ( } 15 \text { a } 20 \% \text { da volemia são perdidos durante o } \\
\text { procedimento) }\end{array}$ & equilíbrio circulatório \\
\hline $\begin{array}{l}\text { Risco de desequilíbrio na } \\
\text { temperatura corporal } \\
\text { Risco de desequilíbrio na } \\
\text { temperatura corporal }\end{array}$ & & medicamentos anestésicos & equilíbrio termo-regulador \\
\hline Risco de aspiração & & nível de consciência reduzido & equilíbrio neurológico \\
\hline Náusea & relato verbal & $\begin{array}{l}\text { irritação gástrica medicamentosa e fatores psicológicos } \\
\text { (ansiedade) }\end{array}$ & equilíbrio digestivo/nutritivo \\
\hline Risco de infecção & & $\begin{array}{l}\text { procedimentos invasivos, defesas secundárias } \\
\text { inadeQuadas (diminuição de hemoglobina), defesas } \\
\text { primárias inadequadas (pele rompida) }\end{array}$ & equilíbrio imunológico \\
\hline $\begin{array}{l}\text { Integridade tissular } \\
\text { prejudicada }\end{array}$ & tecido lesado & cirurgia & integridade cutânea \\
\hline $\begin{array}{l}\text { Risco de lesão } \\
\text { perioperatória de } \\
\text { posicionamento }\end{array}$ & & cirurgia & integridade física \\
\hline Ansiedade & $\begin{array}{l}\text { preocupações expressas, } \\
\text { in̨uietação, ansiedade }\end{array}$ & estresse & equilíbrio psicológico \\
\hline Dor aguda & relato verbal & cirurgia & sensibilidade dolorosa \\
\hline
\end{tabular}

Quadro 1. Diagnósticos de enfermagem, características definidoras e/ou fatores relacionados e necessidade humana básica afetada no período perioperatório. Uberaba (MG), 2008.

\begin{tabular}{|c|c|c|c|}
\hline Diagnóstico & Meta & Objetivos & Prescrições \\
\hline $\begin{array}{l}\text { Risco de volume } \\
\text { deficiente de líeuido }\end{array}$ & $\begin{array}{l}\text { evitar complicações } \\
\text { advindas da perda de } \\
\text { volemia durante cirurgia }\end{array}$ & $\begin{array}{l}\text { compensar perda de líquidos que } \\
\text { ocorre durante cirurgia; } \\
\text { observar sinais sugestivos de } \\
\text { complicações devido à perda de } \\
\text { líquidos }\end{array}$ & $\begin{array}{l}\text { administrar medicamentos conforme prescrição médica, como } \\
\text { drogas vasoativas; } \\
\text { administrar líeuidos e expansores plasmáticos a critério médico; } \\
\text { observar coloração, turgor, elasticidade, temperatura e umidade } \\
\text { cutânea; } \\
\text { monitorar débito urinário, padrão respiratório e circulatório; } \\
\text { realizar registros Quanto à ingesta de líQuidos } \\
\end{array}$ \\
\hline $\begin{array}{l}\text { Risco de desequilíbrio } \\
\text { na temperatura } \\
\text { corporal }\end{array}$ & $\begin{array}{l}\text { manter temperatura } \\
\text { corporal estável }\end{array}$ & controlar hipotermia & $\begin{array}{l}\text { aQuecer a cliente conforme necessidade; } \\
\text { evitar exposição a ambiente frio; } \\
\text { aferir sinais vitais }{ }^{(6,12)}\end{array}$ \\
\hline Risco de aspiração & $\begin{array}{l}\text { impedir a entrada de } \\
\text { secreções gastrintestinais } \\
\text { nas vias } \\
\text { traQueobrônquicas }\end{array}$ & evitar aspiração & $\begin{array}{l}\text { observar nível de consciência da cliente, se inconsciente, lateralizar } \\
\text { a cabeça; } \\
\text { administrar medicação antiemética }^{(6,12)}\end{array}$ \\
\hline Náusea & $\begin{array}{l}\text { restabelecer atividade } \\
\text { nutricional e digestiva }\end{array}$ & $\begin{array}{l}\text { controlar a náusea } \\
\text { manter monitorização nutricional } \\
\text { e hidro-eletrolítica }\end{array}$ & $\begin{array}{l}\text { oferecer alimentos de preferência da cliente; } \\
\text { administrar antieméticos, conforme prescrição médica; } \\
\text { orientar Quanto às práticas Que amenizam a sensação de náusea, } \\
\text { como não permanecer em jejum por períodos prolongados, além de } \\
\text { evitar alimentos Quentes ou gordurosos; } \\
\text { estimular a cliente a manter boa higiene oral, fazendo bochechos } \\
\text { com água bicarbonatada; manter os lábios hidratados; } \\
\text { reduzir ansiedade através de técnicas de relaxamento, manutenção } \\
\text { de ambiente confortável e esclarecimento de dúvidas da cliente; } \\
\text { observar os episódios de náuseas e, no caso de vômitos, avaliar } \\
\text { suas características (cor, consistência, volume, freQuência); } \\
\text { avaliar variações de peso; } \\
\text { monitorar exames laboratoriais (níveis séricos de albumina e } \\
\text { transferrina, hemograma e eletrólitos); } \\
\text { observar alterações hidroeletrolíticas e estimular a hidratação com } \\
\text { líeuidos ricos em potássio e sódio no caso de vômitos } \\
\text { (6-7.12-13) }\end{array}$ \\
\hline
\end{tabular}

Quadro 2. Plano assistencial de enfermagem para período perioperatório. Uberaba (MG), 2008. 


\begin{tabular}{|c|c|c|c|}
\hline Diagnóstico & Meta & Objetivos & Prescrigōes \\
\hline Risco de infecção & $\begin{array}{l}\text { impedir invasão de } \\
\text { microrganismos durante } \\
\text { período perioperatório }\end{array}$ & $\begin{array}{l}\text { diminuir risco de infecção no } \\
\text { pré-operatório } \\
\text { diminuir risco de infecção no } \\
\text { intra-operatório } \\
\text { diminuir risco de infecção no } \\
\text { pós-operatório }\end{array}$ & $\begin{array}{l}\text { realizar preparo intestinal; } \\
\text { realizar tricotomia imediatamente antes da cirurgia e higiene } \\
\text { corporal após esse procedimento; } \\
\text { orientar Quanto à higiene corporal e íntima; } \\
\text { atentar para o uso de técnicas assépticas durante procedimento } \\
\text { anestésico-cirúrgico; } \\
\text { controlar sinais vitais; } \\
\text { avaliar local da incisão cirúrgica, observando presença de secreções } \\
\text { ou exsudatos; } \\
\text { realizar curativo com técnica asséptica uma vez ao dia, lavando } \\
\text { abundantemente com soro fisiológico } 0,9 \% \text { aQuecido e em jato; } \\
\text { realizar higiene íntima cuidadosa; } \\
\text { manipular cateteres, drenos e sonda vesical evitando contaminação; } \\
\text { monitorar equilíbrio hidro-eletrolítico; } \\
\text { monitorar alterações no leucograma } \\
(6,12-13)\end{array}$ \\
\hline $\begin{array}{l}\text { Integridade da pele } \\
\text { prejudicada }\end{array}$ & $\begin{array}{l}\text { restabelecer a integridade } \\
\text { cutânea }\end{array}$ & $\begin{array}{l}\text { promover cicatrização da incisão } \\
\text { cirúrgica }\end{array}$ & $\begin{array}{l}\text { controlar infecção durante período perioperatório; } \\
\text { orientar/realizar higiene corporal; } \\
\text { avaliar aspecto da incisão cirúrgica e observar sinais flogísticos } \\
\text { (presença de hiperemia, calor, dor, edema ou secreção); } \\
\text { observar sinais e sintomas de deiscência; } \\
\text { realizar curativo com técnica asséptica uma vez ao dia, lavando } \\
\text { abundantemente com soro fisiológico } 0,9 \% \text { aQuecido e em jato; } \\
\text { controlar estado nutricional e balanço hidro-eletrolítico; } \\
\text { observar evolução do processo de cicatrizaçãao(6,12,13) }\end{array}$ \\
\hline $\begin{array}{l}\text { Risco de lesão } \\
\text { perioperatória por } \\
\text { posicionamento }\end{array}$ & $\begin{array}{l}\text { prevenir lesão } \\
\text { perioperatória }\end{array}$ & $\begin{array}{l}\text { prevenir complicações } \\
\text { circulatórias } \\
\text { prevenir complicações } \\
\text { neurológicas } \\
\text { prevenir complicações } \\
\text { respiratórias } \\
\text { prevenir lesão por imobilidade } \\
\text { física }\end{array}$ & $\begin{array}{l}\text { controlar hemorragia e hipovolemia; } \\
\text { manter monitorização hemodinâmica; } \\
\text { administrar derivados sanguíneos, medicações vasoativas ou } \\
\text { expansores plasmáticos conforme prescrição médica; } \\
\text { promover perfusão cerebral; } \\
\text { manter monitorização hemodinâmica; } \\
\text { monitorizar sinais vitais, Quadro neurológico e respiratório; } \\
\text { controlar convulsões e sensibilidade periférica } \\
\text { manter monitorização respiratória; } \\
\text { aspirar vias aéreas, se necessário; } \\
\text { prevenir aspiração; } \\
\text { instalar oxigenoterapia, se necessário; } \\
\text { realizar assistência ventilatória, conforme necessidade; } \\
\text { estimular deambulação precoce; } \\
\text { orientar para não permanecer na mesma posição por mais de 2h; } \\
\text { manter roupas de cama limpas, secas e sem dobras; } \\
\text { avaliar integridade cutânea, observando áreas com presença de } \\
\text { hiperemia; } \\
\text { observar integridade cutânea nos locais de proeminência óssea; } \\
\text { utilizar coxins ou colchões especiais, conforme necessidade }\end{array}$ \\
\hline Ansiedade & controlar a ansiedade & reduzir a ansiedade & $\begin{array}{l}\text { estabelecer comunicação verbal e não-verbal com a paciente; } \\
\text { esclarecer dúvidas da paciente; } \\
\text { utilizar técnicas de relaxamento, musicoterapia, estimulação } \\
\text { cutânea, massagem, hipnose, meditação, toQue terapêutico, } \\
\text { distração, acupuntura, ludoterapia, terapia de grupo e terapia com } \\
\text { animais; } \\
\text { ouvir a paciente ativamente; } \\
\text { auxiliar a paciente no enfrentamento da doença; } \\
\text { administrar medicação, conforme prescrição médica; } \\
\text { realizar encaminhamento a outros profissionais, se necessário }{ }^{(6,13)}\end{array}$ \\
\hline Dor aguda & controlar a dor & avaliar a dor & $\begin{array}{l}\text { administrar analgésicos, conforme prescrição médica; } \\
\text { possibilitar ambiente confortável; } \\
\text { realizar técnicas não-medicamentosas, como relaxamento, } \\
\text { musicoterapia, estimulação cutânea, massagem, hipnose, } \\
\text { meditação, toque terapêutico, distração, ludoterapia e acupuntura; } \\
\text { caracterizar a dor (localização, freqüência, intensidade, duração, } \\
\text { Qualidade, fatores Que aumentam e diminuem a dor); } \\
\text { usar instrumentos espećficos para avaliar intensidade da dor; } \\
\text { registrar informações referentes a dor; } \\
\text { discutir com a eQuipe médica sobre escollha da via de medicação e } \\
\text { controle de efeitos colaterais; } \\
\text { informar ao médico sobre evolução da dor }\end{array}$ \\
\hline
\end{tabular}

Continuação do Quadro 2. 
ANEXOS 3 E 4

\begin{tabular}{|c|c|c|c|}
\hline Diagnóstico & Características definidoras & Fatores relacionados & Necessidade humana básica afetada \\
\hline Constipação & $\begin{array}{l}\text { mudança no padrão intestinal, volume e } \\
\text { freeüência de fezes diminuídos, fezes } \\
\text { duras e secas }\end{array}$ & $\begin{array}{l}\text { atividade física insuficiente, tensão } \\
\text { emocional, Quimioterápicos, } \\
\text { hábitos alimentares deficientes, } \\
\text { ingestão insuficiente de fibras e } \\
\text { líquidos }\end{array}$ & equilíbrio intestinal \\
\hline Volume excessivo de líquidos & edema & Quimioterapia & equilíbrio urinário \\
\hline Náusea & relato verbal, aversão à comida & Quimioterapia & equilíbrio digestivo/nutritivo \\
\hline $\begin{array}{l}\text { Nutrição desequilibrada - menos } \\
\text { do Que as necessidades } \\
\text { corporais }\end{array}$ & $\begin{array}{l}\text { relato de ingestão inadequada de } \\
\text { alimentos, falta de interesse por comida }\end{array}$ & náusea, vômitos & equilíbrio nutritivo \\
\hline Fadiga & $\begin{array}{l}\text { falta de energia para manter nível } \\
\text { habitual de atividade física, cansaço, } \\
\text { incapacidade de manter rotinas habituais }\end{array}$ & $\begin{array}{l}\text { estresse, ansiedade, evento } \\
\text { negativo na vida (doença), má } \\
\text { nutrição, anemia }\end{array}$ & equilíbrio de atividade \\
\hline Intolerância à atividade & relato verbal de fadiga ou fraeueza & fraqueza generalizada & equilíbrio de atividade \\
\hline Distúrbio na imagem corporal & perda de parte do corpo (alopecia) & Quimioterapia & equilíbrio na aparência física \\
\hline Risco de infecção & & $\begin{array}{l}\text { procedimentos invasivos, } \\
\text { desnutrição, defesas secundárias } \\
\text { inadeQuadas (diminuição de } \\
\text { hemoglobina) }\end{array}$ & equilíbrio imunológico \\
\hline
\end{tabular}

Quadro 3. Diagnósticos de enfermagem, características definidoras e/ou fatores relacionados e necessidade humana básica afetada durante tratamento Quimioterápico. Uberaba (MG), 2008.

\begin{tabular}{|c|c|c|c|}
\hline Diagnóstico & Meta & Objetivos & Prescrições \\
\hline Constipação & $\begin{array}{l}\text { restabelecer padrão } \\
\text { intestinal }\end{array}$ & controlar constipação & $\begin{array}{l}\text { preferir alimentos ricos em fibras e laxativos; } \\
\text { aumentar a ingesta de líuuidos; } \\
\text { realizar massagem abdominal; } \\
\text { praticar atividades físicas diárias, como caminhadas; } \\
\text { realizar irrigação intestinal; } \\
\text { administrar medicamentos; }\end{array}$ \\
\hline $\begin{array}{l}\text { Volume excessivo de } \\
\text { líeuidos }\end{array}$ & $\begin{array}{l}\text { diminuir retenção de } \\
\text { líeuidos }\end{array}$ & $\begin{array}{l}\text { promover a reeducação } \\
\text { intestinal } \\
\text { aumentar eliminação } \\
\text { urinária de líquidos } \\
\text { avaliar edema }\end{array}$ & $\begin{array}{l}\text { controlar o uso exagerado de enemas, supositórios e laxantes; } \\
\text { estabelecer hábitos regulares de evacuação; } \\
\text { não retardar o momento da evacuação, sempre Que possível }{ }^{(6,7.13)} \\
\text { administrar medicação, conforme prescrição; } \\
\text { treinar hábito urinário; } \\
\text { controlar ingestão hídrica e de sódio; } \\
\text { observar evolução do edema Quanto à intensidade e localização; } \\
\text { identificar variações no peso; } \\
\text { realizar balanço hídrico }^{(10)}\end{array}$ \\
\hline Náusea & $\begin{array}{l}\text { restabelecer atividade } \\
\text { nutricional e digestiva }\end{array}$ & $\begin{array}{l}\text { controlar a náusea } \\
\text { manter monitorização } \\
\text { nutricional e hidro- } \\
\text { eletrolítica }\end{array}$ & $\begin{array}{l}\text { oferecer alimentos de preferência da cliente; } \\
\text { administrar antieméticos, conforme prescrição médica; } \\
\text { orientar Quanto às práticas Que amenizam a sensação de náusea, como não } \\
\text { permanecer em jejum por períodos prolongados, além de evitar alimentos } \\
\text { Quentes ou gordurosos; } \\
\text { estimular a cliente a manter boa higiene oral, fazendo bochechos com água } \\
\text { bicarbonatada; } \\
\text { manter os lábios hidratados; } \\
\text { reduzir ansiedade através de técnicas de relaxamento, manutenção de } \\
\text { ambiente confortável e esclarecimento de dúvidas da cliente; } \\
\text { monitorar sinais vitais; } \\
\text { observar os episódios de náuseas e, no caso de vômitos, avaliar suas } \\
\text { características (cor, consistência, volume, freeüência); } \\
\text { avaliar variações de peso; } \\
\text { monitorar exames laboratoriais (níveis séricos de albumina e transferrina, } \\
\text { hemograma e eletrólitos); } \\
\text { observar alterações hidroeletrolíticas e estimular a hidratação com líQuidos } \\
\text { ricos em potássio e sódio no caso de vômitos }\end{array}$ \\
\hline
\end{tabular}

Quadro 4. Plano assistencial de enfermagem durante tratamento Quimioterápico. Uberaba (MG), 2008. 


\begin{tabular}{|c|c|c|c|}
\hline Diagnóstico & Meta & Objetivos & Prescrições \\
\hline $\begin{array}{l}\text { Nutrição deseQuilibrada } \\
\text { - menos do Que as } \\
\text { necessidades corporais }\end{array}$ & $\begin{array}{l}\text { restabelecer estado } \\
\text { nutricional }\end{array}$ & $\begin{array}{l}\text { controlar peso } \\
\text { monitorar exames } \\
\text { laboratoriais }\end{array}$ & $\begin{array}{l}\text { oferecer alimentos de preferência da cliente; } \\
\text { administrar antieméticos , conforme prescrição médica; } \\
\text { orientar Quanto às práticas Que amenizam a sensação de náusea, como não } \\
\text { permanecer em jejum por períodos prolongados, além de evitar alimentos } \\
\text { Quentes ou gordurosos; } \\
\text { estimular a cliente a manter boa higiene oral, fazendo bochechos com água } \\
\text { bicarbonatada; } \\
\text { manter os lábios hidratados; } \\
\text { reduzir ansiedade através de técnicas de relaxamento, manutenção de } \\
\text { ambiente confortável e esclarecimento de dúvidas da cliente; } \\
\text { realizar encaminhamento ao nutricionista para adeQuação da dieta; } \\
\text { monitorar variações de peso (anterior à doença, no momento do } \\
\text { diagnóstico, durante e após o tratamento); } \\
\text { realizar anotações Quanto aos ganhos e perdas de peso; } \\
\text { realizar exames laboratoriais; } \\
\text { avaliar níveis séricos de albumina e transferrina; } \\
\text { observar alterações no hemograma e eletrólitos } \\
{ }^{(6,7,12,13)}\end{array}$ \\
\hline Fadiga & $\begin{array}{l}\text { restabelecer energia física } \\
\text { para realizar atividades } \\
\text { habituais }\end{array}$ & $\begin{array}{l}\text { melhorar nutrição } \\
\text { controlar a anemia } \\
\text { aliviar sensação de } \\
\text { cansaço } \\
\text { melhorar enfrentamento } \\
\text { da doença }\end{array}$ & $\begin{array}{l}\text { preferir alimentos nutritivos e ricos em energia; } \\
\text { fracionar as refeições; } \\
\text { fornecer suplementos nutricionais; } \\
\text { evitar intervalos prolongados entre as refeições; } \\
\text { oferecer alimentos de preferência da cliente e em apresentações atrativas; } \\
\text { encaminhar a profissional especializado para adequação da dieta; } \\
\text { ingerir alimentos ricos em ferro; } \\
\text { administrar medicação, conforme prescrição médica; } \\
\text { realizar exames laboratoriais; } \\
\text { permanecer em repouso relativo nos momentos de manifestação do } \\
\text { cansaço; } \\
\text { usar fortificantes; } \\
\text { aconselhar a cliente; } \\
\text { esclarecer dúvidas; } \\
\text { ouvir ativamente; } \\
\text { propor estratégias de enfrentamento; } \\
\text { encaminhar para acompanhamento psicológico; } \\
\text { facilitar atitude positiva em relação à doença(7.12) }\end{array}$ \\
\hline Intolerância à atividade & $\begin{array}{l}\text { melhorar tolerância à } \\
\text { execução de atividades }\end{array}$ & $\begin{array}{l}\text { reduzir sensação de } \\
\text { fraQueza } \\
\text { facilitar } \\
\text { desempenho de } \\
\text { atividades }\end{array}$ & $\begin{array}{l}\text { ingerir alimentos nutritivos e energéticos, fracionados em várias refeições; } \\
\text { fornecer suplementos nutricionais; } \\
\text { controlar anemia, ingerindo alimentos ricos em ferro; } \\
\text { avaliar fatores Que aumentem ou reduzem a sensação de fraqueza; } \\
\text { adaptar atividades ao estado geral da cliente; } \\
\text { estabelecer metas para realização de atividades habituais, como aQuelas } \\
\text { relacionadas ao autocuidado }{ }^{(7,12,13)}\end{array}$ \\
\hline $\begin{array}{l}\text { Distúrbio na imagem } \\
\text { corporal }\end{array}$ & melhorar auto-imagem & $\begin{array}{l}\text { reforçar cuidados com o } \\
\text { couro cabeludo }\end{array}$ & $\begin{array}{l}\text { orientar sobre estratégias de adaptação como uso de gorros, perucas e } \\
\text { lenços; } \\
\text { evitar secador ou produtos Químicos, como permanentes, tinturas; } \\
\text { oferecer esclarecimentos sobre a transitoriedade do problema; } \\
\text { reforçar as iniciativas de superação do problema e estresse decorrente; } \\
\text { fornecer suporte emocional; } \\
\text { evitar exposição ao sol a fim de evitar Queimaduras; } \\
\text { realizar higiene do couro cabeludo; } \\
\text { usar xampus suaves; } \\
\text { evitar secador ou ferros de encaracolar os cabelos, tinturas ou permanentes; } \\
\text { proteger o couro cabeludo em tempos de frio contra a perda de calor }{ }^{(7,12)}\end{array}$ \\
\hline Risco de infecção & $\begin{array}{l}\text { impedir a invasão por } \\
\text { microrganismos } \\
\text { patogênicos durante } \\
\text { tratamento } \\
\text { Quimioterápico }\end{array}$ & $\begin{array}{l}\text { prevenir infecção durante } \\
\text { tratamento } \\
\text { Quimioterápico }\end{array}$ & $\begin{array}{l}\text { orientar a cliente Quanto à importância de manter um estado nutricional } \\
\text { adequado; } \\
\text { orientar a cliente Quanto à lavagem das mãos antes e após as refeições, } \\
\text { depois de usar o banheiro e antes de Qualouer atividade de autocuidado; } \\
\text { evitar o contato da cliente com pessoas recentemente imunizadas com } \\
\text { vacinas de vírus vivos atenuados; } \\
\text { evitar contato da cliente com pessoas Que apresentem alguma doença } \\
\text { transmissível; } \\
\text { orientar a equipe Quanto a técnicas assépticas no preparo e administração } \\
\text { dos Quimioterápicos; } \\
\text { monitorar hemograma e leucograma; } \\
\text { tratar anormalidades hematológicas (leucopenia ou anemia). }{ }^{(6,12,13)}\end{array}$ \\
\hline
\end{tabular}

\section{Continuação do Quadro 4.}


ANEXOS 5 E 6

\begin{tabular}{|l|lll|}
\hline Diagnóstico & Características definidoras & Fatores relacionados & Necessidade humana básica afetada \\
\hline $\begin{array}{l}\text { Nutrição desequilibrada: mais do } \\
\text { Que as necessidades corporais }\end{array}$ & $\begin{array}{l}\text { peso } 20 \% \text { acima do ideal para a altura e } \\
\text { a compleição, nível de atividade } \\
\text { sedentário }\end{array}$ & $\begin{array}{l}\text { ingestão excessiva em relação às } \\
\text { necessidades metabólicas }\end{array}$ & eQuilíbrio nutritivo \\
\hline Estilo de vida sedentário & $\begin{array}{l}\text { escolhe uma rotina diária sem exercícios } \\
\text { físicos }\end{array}$ & falta de tempo & eQuilíbrio da atividade \\
\hline
\end{tabular}

Quadro 5. Diagnósticos de enfermagem no período pós-tratamento. Uberaba (MG), 2008.

\begin{tabular}{|c|c|c|c|}
\hline Diagnóstico & Meta & Objetivos & Prescrições \\
\hline $\begin{array}{l}\text { Nutrição desequilibrada: } \\
\text { mais do Que as } \\
\text { necessidades corporais }\end{array}$ & controlar o peso & $\begin{array}{l}\text { ingerir nutrientes em } \\
\text { acordo com necessidades } \\
\text { metabólicas } \\
\text { realizar atividades físicas } \\
\text { diárias } \\
\text { reduzir ansiedade }\end{array}$ & $\begin{array}{l}\text { manter dieta adeQuada, rica em frutas e verduras e pobre em gorduras e } \\
\text { calorias; } \\
\text { fracionar a dieta em peQuenas porções várias vezes ao dia ( } 3 \text { em 3h); } \\
\text { escolher uma fruta no lanche; } \\
\text { comer devagar; } \\
\text { não assistir televisão enQuanto come; } \\
\text { usar produtos dietéticos; } \\
\text { encaminhar ao nutricionista para adeQuação da dieta; } \\
\text { orientar Quanto à importância de atividades físicas diárias, como } \\
\text { caminhadas; } \\
\text { utilizar roupas e calçado apropriados para atividade física; } \\
\text { orientar Quanto ao alongamento antes do início da atividade física; } \\
\text { encaminhar ao profissional Qualificado para as devidas orientações; } \\
\text { orientar Quanto a técnicas de relaxamento, musicoterapia, estimulação } \\
\text { cutânea, massagem, hipnose, meditação, toQue terapêutico, distração, } \\
\text { acupuntura, ludoterapia, terapia de grupo e terapia com animais; } \\
\text { ouvir a paciente ativamente; } \\
\text { auxiliar a paciente no enfrentamento da doença; } \\
\text { administrar medicação, conforme prescrição médica; } \\
\text { realizar encaminhamento a outros profissionais, se necessário }\end{array}$ \\
\hline Estilo de vida sedentário & $\begin{array}{l}\text { aumentar nível de } \\
\text { atividade física }\end{array}$ & $\begin{array}{l}\text { incluir atividades físicas } \\
\text { na rotina diária } \\
\text { avaliar a perda de peso }\end{array}$ & $\begin{array}{l}\text { informar sobre os benefícios da atividade física sobre a saúde e bem estar } \\
\text { físico e mental; } \\
\text { mudar hábitos, como usar as escadas em vez do elevador, não passar } \\
\text { muito tempo deitado ou sentado, sempre Que possível, preferir ir } \\
\text { caminhando a algum lugar em vez de usar o automóvel; } \\
\text { fazer trinta minutos de atividade física moderada por dia; } \\
\text { preferir exercícios ae róbios ao de levantamento de peso; } \\
\text { utilizar roupas e calçado apropriados para atividade física; } \\
\text { orientar Quanto ao alongamento antes do início da atividade física; } \\
\text { encaminhar ao profissional Qualificado para as devidas orientações; } \\
\text { pesar na mesma balança, no mesmo horário, uma vez por semana e anotar } \\
\text { a perda de peso; } \\
\text { realizar avaliação em profissional Qualificado a cada dois meses }\end{array}$ \\
\hline
\end{tabular}

Quadro 6. Plano assistencial de enfermagem para diagnósticos de enfermagem no período pós-tratamento. Uberaba (MG), 2008. 